\title{
Plasma-Chemical and Photo-Catalytic Degradation of Bromophenol Blue
}

\author{
Serge Alain Djepang ${ }^{1}$, Samuel Laminsi ${ }^{1{ }^{1 *},}$ Estella Njoyim-Tamungang ${ }^{1}$, \\ Cedrik Ngnintedem ${ }^{1}$, Jean-Louis Brisset ${ }^{2}$ \\ ${ }^{1}$ Inorganic Chemistry Department, University of Yaoundé I, P.O. Box 812, Yaoundé, Cameroon \\ ${ }^{2}$ University of Rouen, 76821 Mont Saint-Aignan, France \\ *Corresponding author: s.laminsi@yahoo.fr
}

Copyright (C) 2014 Horizon Research Publishing All rights reserved.

\begin{abstract}
The acid and oxidizing properties of a non-thermal plasma in humid air (e.g., a gliding arc device) have been investigated in the degradation of aqueous solutions of bromophenol blue. The plasma treatment was coupled with $\mathrm{TiO}_{2}$ as a photocatalyst with and without oyster shell powder for acidity control. The degradation kinetics were studied under various conditions such as treatment times, concentration of solution, type and concentration of catalyst. The removal of the dye was carried out with and without $\mathrm{TiO}_{2}$ and oyster shell: maximum degradation was attained for $20 \mathrm{~min}$ of treatment at an initial $\mathrm{pH}=2.4$ for 3 g.L $\mathrm{L}^{-1} \mathrm{TiO}_{2}$ concentration $(61.21 \%)$ and 0.4 g.L $\mathrm{L}^{-1}$ Oyster shell concentration $(28.48 \%)$. Temporal post-discharge phenomena induced by the plasma treatment are also observed, which are both ascribed to species formed in the discharge (i.e...respectively $\mathrm{H}_{2} \mathrm{O}_{2}$ or $\mathrm{NOx}$ derivatives). After daily post-discharge studies for one week, the removal efficiencies ranged from $61.21 \%$ up to $82.05 \%$ in the case of $\mathrm{TiO}_{2}$ and oyster shell gives $70.9 \%$ for the same period.
\end{abstract}

Keywords Gliding Arc Plasma, Bromophenol Blue, Titanium Oxide, Oyster Shell, Temporal Post-Discharge

\section{Introduction}

Organic dyes are a well known source of environmental pollution and therefore their removal from waste waters receives increasing attention. One major source of these wastes comes from the industrial process effluents, such as these provided by paper, plastic, textile, natural and artificial fibers industries[1]. Bromophenol blue (BPB) is a good example of industrial dye deriving from triphenylmethane. Its highest concentration of Bromophenol Blue (BPB) in industrial wastes could reach a maximum of $50 \mathrm{mg} . \mathrm{L}^{-1}[2]$ for periods of intense industrial activities. A substantial amount of dyestuff is lost during the dyeing process in the textile industry poses a major problem for its removing; its presence is also an actual threat for environment. A number of physical, biochemical oxidation and chemical techniques had been reported for the treatment of all types of dyes with limited success. Biodegradation of dyes is not efficient enough due to the presence of complex and stable aromatic structures of the numerous rings present in dye molecules, so that advanced oxidation processes (AOPs) have been investigated as an alternative [3]. One of the most recent development of AOPs is concerned with using electrical discharges and the relevant chemical properties of the active species present in a cold plasma. Abdelmalek [4] showed that representatives of all types of dyes were degraded on being exposed to a non-thermal plasma, such as a gliding arc discharge. Other single techniques were proposed such as using walnut shells as an adsorbent [5]. Besides, the action of oyster shell powder (OS) was recently combined with gliding electric discharge used to abate pollution of surface waters sampled which collected industrial and domestic wastes from large Cameroonian cities [6]. During the past two decades, photocatalytic processes involving $\mathrm{TiO}_{2}$ semiconductor particles under UV light illumination have been shown to be potentially advantageous and useful for degrading waste water pollutants. The advantage of using $\mathrm{TiO}_{2}$ as a photocatalyst lies in its ability to degrade toxic organic compounds [7], reduce metallic ions [8], improve the biodegradability of cellulosic effluents [9] and bleach a variety of dyes in solution [10-12] or in solid mixtures [13]. Its basic efficiency can be enhanced by doping [14]. Hence, combined plasmachemical treatment and $\mathrm{TiO}_{2}$-mediated heterogeneous processes may be very efficient for both decolourization and degradation [15]. On exposing $\mathrm{TiO}_{2}$ suspensions to ultraviolet light, electrons are raised to the conduction band from the valence band, and generate positive holes and electrons:

$$
\mathrm{TiO}_{2}+\mathrm{h} v(<400 \mathrm{~nm}) \rightarrow \mathrm{TiO}_{2}+\left(\mathrm{e}^{-}+\mathrm{h}^{+}\right)
$$

Electrons and holes can recombine according to "(2)" or react with other molecules, such as oxygen, and generate reactive superoxide anions "(3)". 


$$
\begin{aligned}
\mathrm{TiO}_{2}+\left(\mathrm{e}^{-}+\mathrm{h}^{+}\right) & \rightarrow \mathrm{TiO}_{2}+\text { heat } \\
\mathrm{TiO}_{2}+\left(\mathrm{e}^{-}\right)+\mathrm{O}_{2} & \rightarrow \mathrm{TiO}_{2}+\mathrm{O}_{2}
\end{aligned}
$$

The positive holes can react with electron donors in the solution to produce adsorbed hydroxyl radicals (Reactions "(4)" and "(5)" ) or directly oxidize organic matter (OM) at the semi-conductor surface "(6)"

$$
\begin{array}{rr}
\mathrm{TiO} 2(\mathrm{~h}+)+\mathrm{H} 2 \mathrm{O}(\text { ads }) \rightarrow \mathrm{TiO} 2+\mathrm{H}++\mathrm{OHads} \bullet \\
\mathrm{TiO} 2(\mathrm{~h}+)+\mathrm{HO}-(\text { ads }) \rightarrow & \mathrm{TiO} 2+\text { OHads } \bullet \\
\mathrm{TiO} 2(\mathrm{~h}+)+\text { OM degradation intermediates } \rightarrow & \mathrm{TiO} 2+ \\
\mathrm{OM} \bullet+
\end{array}
$$

The hydroxyl radicals generated in the process are strong oxidizers and they react quickly with the organic matter adsorbed on the catalyst "(7)", forming oxidized intermediates. A complete mineralization can be achieved for adequate treatment times.

$\mathrm{MO}+\mathrm{OH}_{\mathrm{ads}}{ }^{\bullet} \rightarrow$ degradation intermediates $\rightarrow \mathrm{CO}_{2}+\mathrm{H}_{2} \mathrm{O}$

$$
+ \text { salts }
$$

In this paper, we examine the degradation of BPB by electric discharges at atmospheric pressure and quasi room temperature. Special attention is devoted to the acidity control of the BPB solution. This action is considered with and without the presence of titanium dioxide $\left(\mathrm{TiO}_{2}\right)$ as a photo-catalyst and oyster shell (OS) powder as an acidity buffer medium. Subsequent delayed bleaching and degrading effects were also observed after switching off the discharge, i.e., in temporal post-discharge conditions.

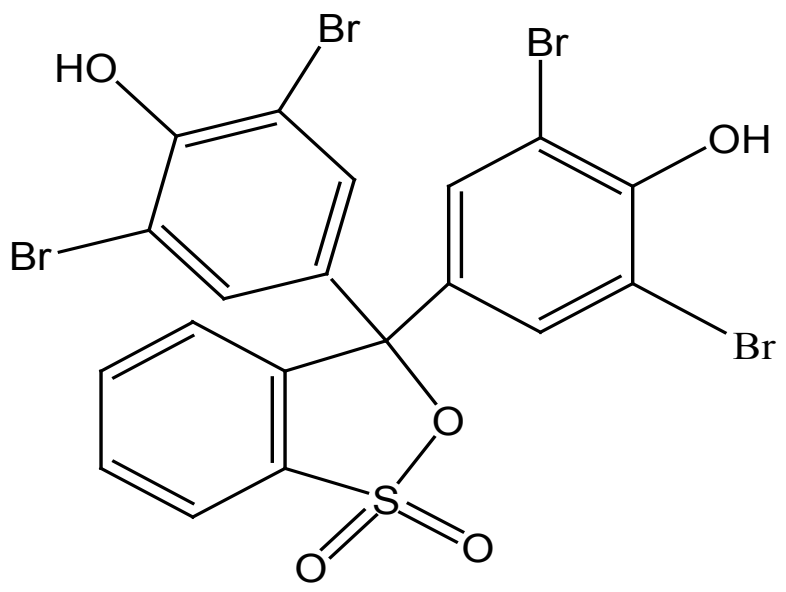

Figure 1. The acid structure of Bromophenol blue (BPB)

\section{Materials and Methods}

\subsection{Materials and Reagents}

Bromophenol Blue $\left(\mathrm{C}_{19} \mathrm{H}_{10} \mathrm{Br}_{4} \mathrm{O}_{5} \mathrm{~S}\right)$ or $3,3,5,5^{\prime}$ tetrabromo phenolsulphonphthalein, molar mass $670.0 \mathrm{~g}$ was purchased from Merck's and was used without any further purification to prepare a stock solution of known concentration. Solutions of textile dyes were prepared using distilled water to obtain the desired concentration of BPB, i.e., 10 and $50 \mathrm{mg} . \mathrm{L}^{-1}$; it is characterized by the wavelengths of the UV-vis absorption peaks $(\lambda=438 \mathrm{~nm}$ and $591 \mathrm{~nm}$ for acid and basic forms respectively). The acidity constant of $\mathrm{BPB}$ is reported close to $\mathrm{pK}_{\mathrm{a}}=4.06$ at ionic strength 0.01 $\mathrm{molL}^{-1}$ and room temperature. The $\mathrm{pH}$ transition interval of BPB lies between $\mathrm{pH} 3.0$ (yellow) and $\mathrm{pH} 4.6$ (purple). The chemical structure (Fig. 1) and absorption spectra (Fig. 2) of $\mathrm{BPB}$ in different forms in solution are shown.

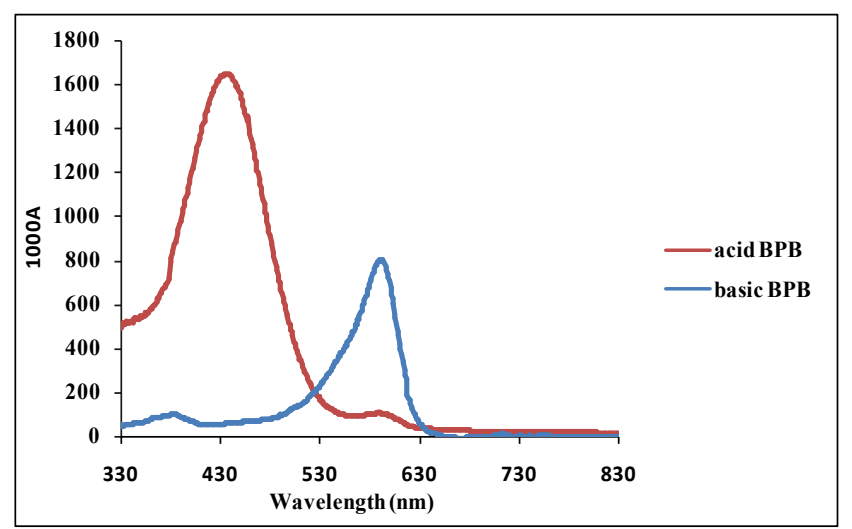

Figure 2. Uv-vis absorption spectra of BPB

The standard oxidation potential of most organic compounds is found close to $0.5 \mathrm{~V} / \mathrm{SHE}$; the matching value for Triphenylcarbinol is reported at $0.3 \mathrm{~V} / \mathrm{SHE}$ and that of the $\mathrm{C}_{6} \mathrm{H}_{4} \mathrm{COH}\left(\mathrm{C}_{6} \mathrm{H}_{4}\right)_{2} \mathrm{O}$ close to $0.1 \mathrm{~V} / \mathrm{SHE}$ [16]. This value is arbitrary attributed to BPB.

The photocatalyst $\mathrm{TiO}_{2}$ was obtained from Riedel-de-Haën (Degussa P25) and mainly contained the anatase form. Oyster shells (OS) are waste products from aquaculture that present a major disposal problem in coastal regions such as southeast Korea. Also, specialized press reported that a Japanese fish farmer tossed OS into a pond and found out that it cleared dirty water [17]. For the present study, the collected shells were washed, sun dried, mechanically crushed in a porcelain mortar, and sieved with a mesh size $0.5 \mathrm{~mm}$ before used in plasma treatment. The shells were not pyrolyzed.

\subsection{Apparatus}

The gliding discharge (or "glidarc") was proposed by Lesueur et al $[18,19]$ and developed by Czernichowsky et al $[20,21]$ for the treatment of gases. The reactor consists of two or more diverging electrodes, ie., the electrodes disposed in a gas at atmospheric pressure and connected to a suitable energy source, generally a high voltage leak transformer (5 $10 \mathrm{kV})$. An arc forms at the narrowest gap between the electrodes [22]. A gas flow directed along the axis of the electrodes gently pushes the arc feet along the conductors, so that the arc length increases until breaking in a plasma plume and its temperature decreases, as does its energy, when the arc is short-circuited by a new one (Fig. 3). 


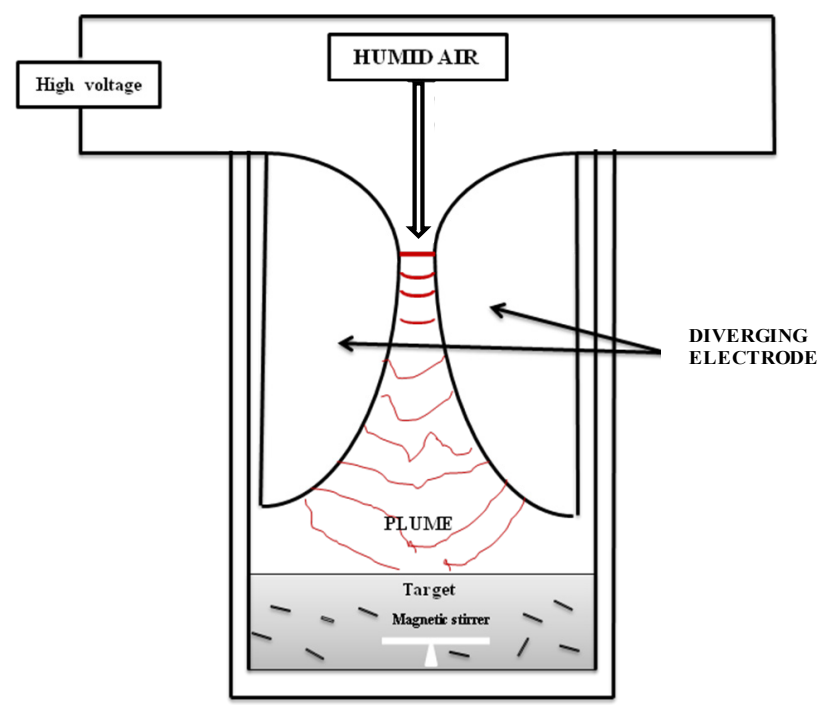

Figure 3. Scheme of the gliding arc batch reactor

The resulting plasma is actually a quenched plasma, similar to non-thermal plasma, and operated at atmospheric pressure and at a (macroscopic) temperature which does not exceed $60^{\circ} \mathrm{C}$. A circulating water flow controls the temperature of the liquid target at $25^{\circ} \mathrm{C}$ [23] and limits evaporation. Working parameters such as the nature and flow rate of the input gas, the electrodes material, and the organic solute play important roles in the degradation of organic pollutants. The input gas used is water-saturated air. Air is provided by a compressor, it passes through a bubbling Duran flask that is filled with distilled water and becomes saturated. The choice of this gas is governed by economy and by the nature of the expected chemical properties of the mixture $\mathrm{O}_{2}, \mathrm{~N}_{2}$, and $\mathrm{H}_{2} \mathrm{O}$ [22]. Emission spectroscopy measurements on gliding arc plasma in humid air revealed the simultaneous presence of $\bullet \mathrm{OH}$ and $\bullet \mathrm{NO}$ radicals in the discharge, with a much higher density for $\bullet \mathrm{OH}$ radicals than for $\bullet \mathrm{NO}$ [24]. More recent investigations with the LIFS technique $[25,26]$ showed that $\bullet \mathrm{OH}$ was present in bubbles formed with immersed electrode reactors and led to estimate the lifetime in the range 700-1100 ns [24]. The presence of -OH was also identified [26] in aqueous solutions exposed to immersed discharges, but not evidenced in solutions disposed under the discharge, probably due to the short half-life time of the radical in water or the limited temperature of the medium. The species formed in gliding arc discharge such as $\bullet \mathrm{OH}$ radicals (and its dimer $\mathrm{H}_{2} \mathrm{O}_{2}$ ) are responsible for strong oxidizing effects whereas acidifying properties are due to the $\cdot \mathrm{NO}$ radicals $[24,27]$. When aqueous solutions are exposed to such plasma, chemical reactions occur at the liquid/gas interface and develop in the liquid target. The solute is thus subjected to the chemical properties of the impinging activated species provided they are water soluble (Reaction "(8)"- "(18)"). The diffusion process in the liquid is improved by conversion in the liquid phase due to the air flow and magnetic stirring.

$$
\mathrm{H} 2 \mathrm{O}+\mathrm{e}-\rightarrow \mathrm{H} \bullet+\mathrm{OH} \bullet+\mathrm{e}-
$$

$$
\begin{array}{r}
\mathrm{O} 2+\mathrm{e}-\rightarrow \cdot \mathrm{O}(3 \mathrm{P})+\bullet \mathrm{O}(1 \mathrm{D})+\mathrm{e}- \\
\mathrm{N} 2+\mathrm{e}-\rightarrow+\mathrm{N}(4 \mathrm{~S})+\bullet \mathrm{N}(2 \mathrm{D})+\mathrm{e}- \\
\bullet \mathrm{N}(2 \mathrm{D})+\mathrm{O} 2 \rightarrow \mathrm{NO} \bullet+\bullet \mathrm{O} \\
\mathrm{H} \bullet+\mathrm{O} 2 \rightarrow \mathrm{HO} 2 \bullet \\
\mathrm{HO} 2 \bullet+\mathrm{NO} \bullet \rightarrow \mathrm{NO} 2+\mathrm{HO} \bullet \\
\mathrm{NO} 2 \bullet+\mathrm{HO} \bullet \rightarrow \mathrm{H}++\mathrm{NO} 3 \\
\mathrm{NO} \bullet+\mathrm{HO} \bullet \rightarrow \mathrm{HNO} 2 \\
\mathrm{HNO} 2 \rightarrow \mathrm{H}++\mathrm{NO} 2 \\
\mathrm{NO} \bullet+\bullet \mathrm{O}(3 \mathrm{P}) \rightarrow \mathrm{NO} 2 \\
\mathrm{O} 2+\bullet \mathrm{O}(3 \mathrm{P}) \rightarrow \mathrm{O} 3
\end{array}
$$

\subsection{Procedure And Analytical Methods}

A volume of $430 \mathrm{~mL}$ of aqueous solutions of Bromophenol Blue (50mg. $\mathrm{L}^{-1}$ ) was introduced in the reactor and the air flow rate fixed at $800 \mathrm{~L}^{-1} \mathrm{~h}^{-1}$. The treatments of the dye solutions are investigated as a function of the exposure time $t^{*}(\mathrm{~min})$ by keeping constant all the other working parameters. The treatment times are respectively: 5 -10- 1520- 25 and $30 \mathrm{~min}$. The solutions were exposed to the discharge without and with incorporated solids: $\mathrm{TiO}_{2}$ (at 0.5 1- 1.5- 2- 2.5 and 3g. $\mathrm{L}^{-1}$ concentration) and Oyster Shell (at $0.1-0.2-0.3-0.4-0.5$ and $0.6 \mathrm{~g} . \mathrm{L}^{-1}$ concentration) with the aim of optimising the quantity of catalyst. The suspension was stirred for $30 \mathrm{~min}$ in the dark to attain adsorption equilibrium between the dye solution and $\mathrm{TiO}_{2}$ or $\mathrm{OS}$ powder. Before analysis, the aqueous samples were centrifuged to remove $\mathrm{TiO}_{2}$ and Oyster Shell agglomerates. The simple plasma and plasmacatalyst treatments required the same energy expenses because the discharge was operated for the same time $t^{*}$ : direct comparison of the efficiency of the processes can thus be achieved. The UV/VIS spectrophotometer used for the determination of dye disappearance kinetics was an "Aqualytic" UV/VIS spectrometer recording the spectra over the 330-900 nm range. Calibration plots based on the Beer-LambertBouguer's law were obtained by relating the absorbance to the concentration. Each plot was determined at the maximum of absorbance peak of the dye. The chemical analyses of the shells were performed with an inductively coupled plasma atomic emission spectroscopy device after dissolution in $\mathrm{HCl}$ or $\mathrm{HNO}_{3}$.

\section{Results}

\subsection{Acidity Control}

The variation of absorbance of basic BPB solution with the exposure time is presented in Fig. 4. We may then consider that the formation of protons takes place at the gas-liquid interface, before the protons and the matching nitrates drift into the bulk solution. 
The spectral changes observed for various exposure times to the discharge illustrate the matching acid evolution of the solution (Fig. 4). The peak at $591 \mathrm{~nm}$ is the main absorption band of the unbleached molecule in aqueous solution for $\mathrm{pH}>$ $\mathrm{pK}_{\mathrm{a}}$. In strongly acidic solution, i.e., when the treated solution turns to become acidic because of the formation of $\mathrm{HNO}_{3}$, this band disappears and a broader one appears at $\lambda_{\max }=438 \mathrm{~nm}$ as the colour readily changes from purple to yellow (Fig. 4).

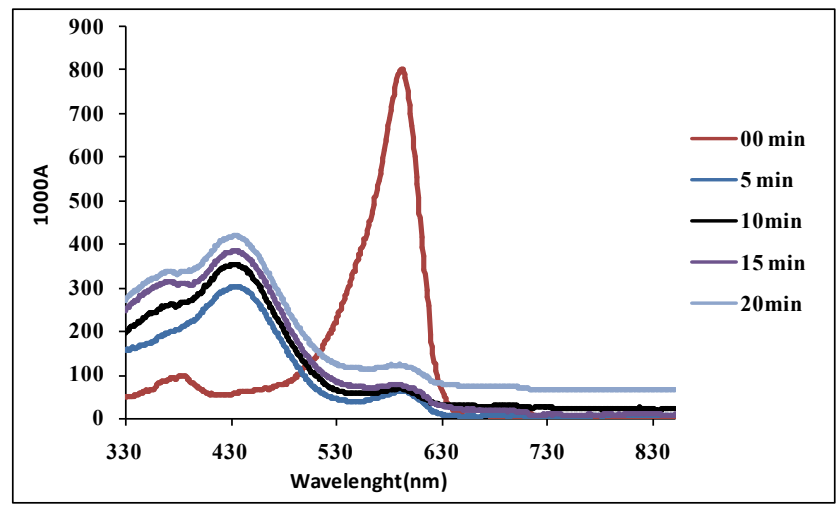

Figure 4. Variation of absorbance spectra of basic BPB solutions with the exposure time $t *$ to the discharge $(t *(\min )=0-5-10-15-20)$

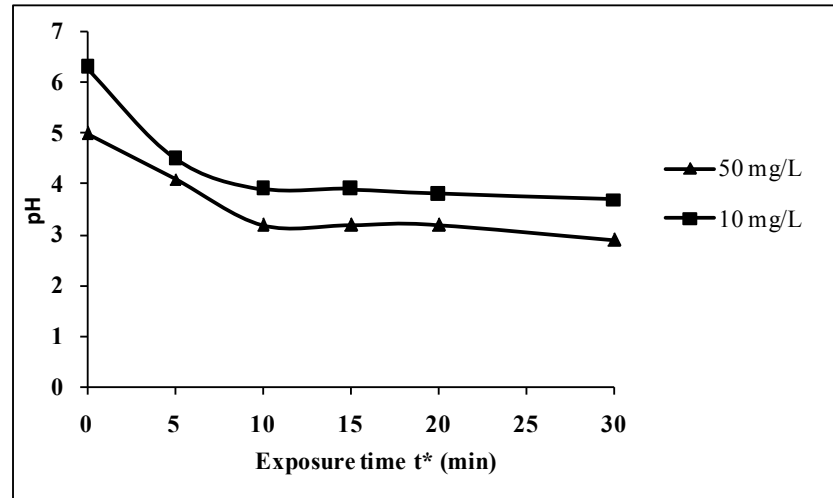

Figure 5. Evolution of $\mathrm{pH}$ of the BBP solution with the exposure time $\mathrm{t}^{*}$ (min) for various concentrations

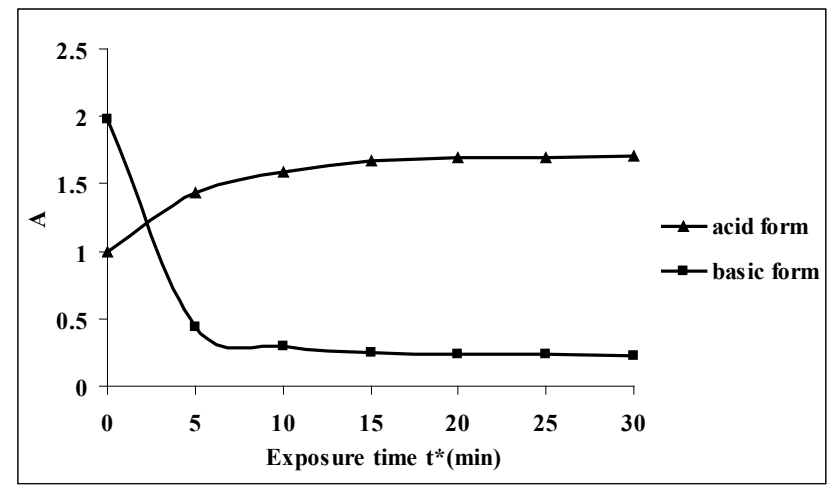

Figure 6. Evolution of the absorbance against time relevant to discharge $\left(\mathrm{t}^{*} \leq 30 \mathrm{~min}\right)$

Exposing to the discharge for 10min two BBP solution (10 and 50mg. $\mathrm{L}^{-1}$ ) also induces an immediate $\mathrm{pH}$ lowering from
pH: 6.3- 5.2 to 3.9- 3.2 as shown in Fig. 5, a feature in agreement with the acid effects of the discharge, and due to the occurrence of nitric acid. It is worth mentioning that a growing shoulder appears around 350nm (Fig. 4) and may be tentatively attributed to transient nitrites [28]. This spectral study is a new illustration of the phenomenon of acidity in plasma discharge and confirms the acidification process of BPB.

The absorbance changes from the basic to the acid peaks (591 to $438 \mathrm{~nm}$ ) with the exposure time (Fig. 6) and the decrease in the "acid" peak enable us to develop a kinetic study of the evolution. Turning into the acid medium induces the disappearance of the basic form and the appearance of the matching acid form of the dye.

\subsection{Direct Degradation of BPB by Plasma without Adding of Solids (TiO $_{2}$ And Oyster Shells)}

The UV/vis absorbance spectra of the untreated acid solution of BPB $\left(50 \mathrm{mg} \cdot \mathrm{L}^{-1}\right.$ at $\left.\mathrm{pH}=2.4\right)$ show a main peak at $438 \mathrm{~nm}$ (Fig. 7) the intensity of which decreases as the exposure time to the discharge increases.

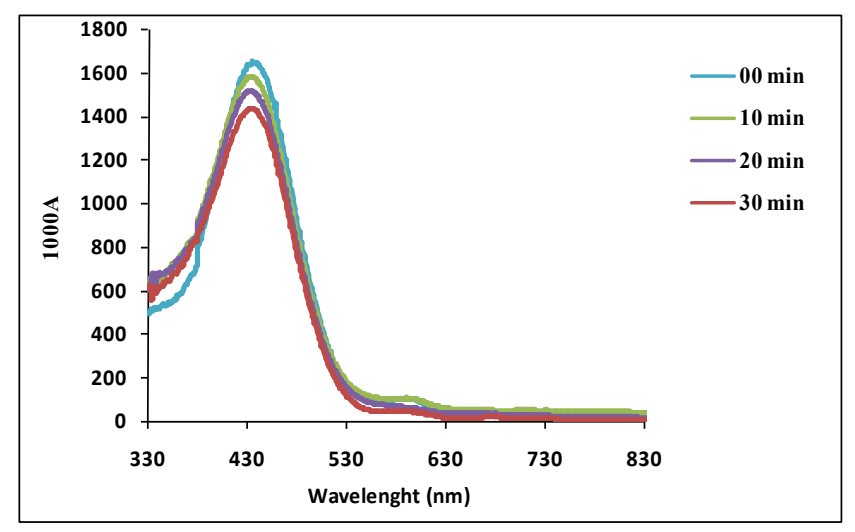

Figure 7. Evolution of absorbance spectra of acid BPB solutions with the exposure time $\mathrm{t} *$ to the discharge $(\mathrm{t} *(\mathrm{~min})=0-10-20-30)$

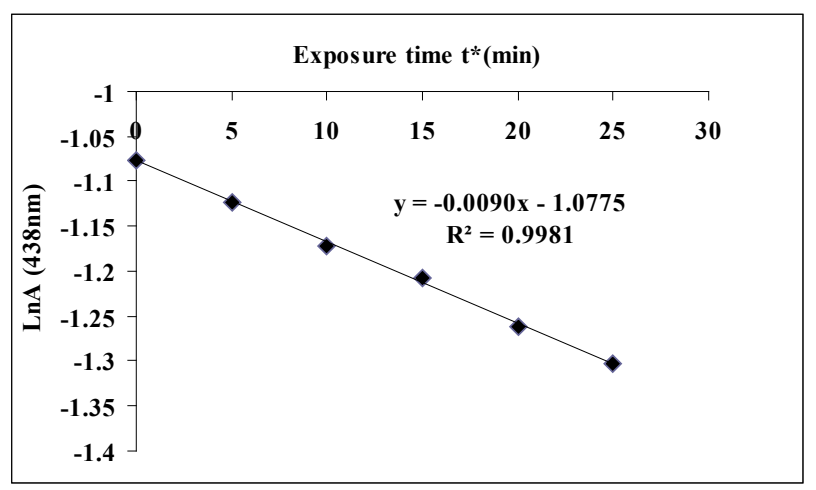

Figure 8. Kinetics of acid BPB solutions exposed to the discharge for $\mathrm{t}^{*}$ min (dye concentration $10 \mathrm{mg} . \mathrm{L}^{-1} ; \mathrm{pH} 2.4$ )

This behaviour is interpreted by the degradation of the dye. A new set of experiments performed on a dilute acid solution (dye concentration $10 \mathrm{mgL}^{-1} ; \mathrm{pH} 2.4$ ) confirmed the decrease of the peak intensity and an assumed pseudo first order 
kinetic process accounts for the evolution with the exposure time. The relevant $k_{1}$ constant given by the slope of the logarithm transform Ln $\left(\mathrm{A}_{438}\right)$ vs $\mathrm{t}^{*}$ is $0.009 \mathrm{~min}^{-1}$ (Fig. 8) with a good accuracy.

\subsection{Influence of $\mathrm{TiO}_{2}$ on BPB Plasma Treatment}

The influence of the photocatalyst on the plasma treatment of $50 \mathrm{mg} \mathrm{L}^{-1}$ of BPB (initial $\mathrm{pH} 2.4$ ) was thus investigated with various concentrations of $\mathrm{TiO}_{2}$ for a standard exposure time $t^{*}=20$ min to the discharge.

Table 1. Degradation rate for the plasmacatalytic treatment of BPB by $\mathrm{TiO}_{2}\left(\mathrm{t}^{*}=20 \mathrm{~min}\right)$

\begin{tabular}{|c|c|}
\hline TiO2 concentration (g.L-1) & Degradation rate (\%) \\
\hline 0 & 15.15 \\
\hline 0.5 & 25.81 \\
\hline 1.0 & 39.81 \\
\hline 1.5 & 42.30 \\
\hline 2.0 & 46.18 \\
\hline 2.5 & 56.79 \\
\hline 3.0 & 61.21 \\
\hline
\end{tabular}

The resulting percent abatement in the dye concentration $\Delta \mathrm{C} / \mathrm{C}_{0}, \%$ (Table 1) increases with the incorporated mass of $\mathrm{TiO}_{2}, \mathrm{C}\left(\mathrm{TiO}_{2}\right), \mathrm{gL}^{-1}$ according to a reasonably linear relationship:

$$
\Delta \mathrm{C} / \mathrm{C} 0=14.82 \mathrm{C}(\mathrm{TiO} 2)+18.66 \quad\left(\mathrm{R}^{2}=0.97\right)
$$

Incorporating $3 \mathrm{~g} . \mathrm{L}^{-1}$ of $\mathrm{TiO}_{2}$ to the acid $\mathrm{BPB}\left(50 \mathrm{mg} \cdot \mathrm{L}^{-1}\right)$ solution induces an abatement higher than $60 \%$ for $\mathrm{t}^{*}=20$ min, while the abatement was less than $20 \%$ in the absence of the photocatalyst. The absorption spectra without and with different concentration of $\mathrm{TiO}_{2}$ are given in Fig. 9. The absorption band at $438 \mathrm{~nm}$ generally decreases with an increase of the $\mathrm{TiO}_{2}$ catalyst's mass.

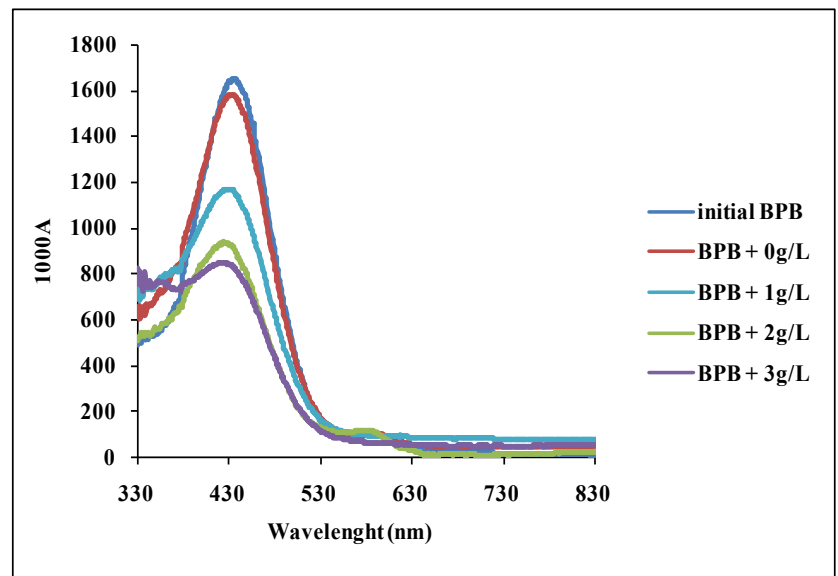

Figure 9. Variation of absorbance spectra of acid BPB solutions with mass of $\mathrm{TiO}_{2}\left(\right.$ exposure time $\left.\mathrm{t}^{*}(\mathrm{~min})=20\right)$.

\subsection{Composition and Structure of the Oyster Shell}

The chemical analyses of the shells (Table 2 ) revealed that calcium is the main component present as aragonite and mainly as calcite, that is, as carbonates, which were identified by X-ray diffraction and FTIR spectroscopy.

Table 2. Results of Chemical Analysis of Natural Oyster Shells

\begin{tabular}{|c|c|c|}
\hline Oxide of elements & \% oxide in OS(HCl) & $\begin{array}{c}\text { \% oxide in } \\
\left.\text { OS( } \mathrm{HNO}_{3}\right)\end{array}$ \\
\hline $\mathrm{Al}_{2} \mathrm{O}_{3}$ & 0.33 & 0.4 \\
\hline $\mathrm{Fe}_{2} \mathrm{O}_{3}$ & 0.20 & 0.04 \\
\hline $\mathrm{CuO}$ & 0.37 & 0.19 \\
\hline $\mathrm{PbO}$ & $\mathrm{nd}$ & nd \\
\hline $\mathrm{ZnO}$ & 0.58 & nd \\
\hline $\mathrm{MgO}$ & $\mathrm{nd}$ & nd \\
\hline $\mathrm{CaO}$ & 96.61 & 83.02 \\
\hline $\mathrm{SiO}_{2}$ & 0.60 & 0 \\
\hline $\mathrm{MoO}_{3}$ & 0.37 & 0.07 \\
\hline $\mathrm{B}_{2} \mathrm{O}_{3}$ & 0.14 & 0.14 \\
\hline $\mathrm{P}_{2} \mathrm{O}_{5}$ & $\mathrm{nd}$ & $\mathrm{nd}$ \\
\hline $\mathrm{Na}_{2} \mathrm{O}$ & $\mathrm{nd}$ & nd \\
\hline $\mathrm{H}_{2} \mathrm{O}$ & $\mathrm{nd}$ & $\mathrm{nd}$ \\
\hline $\mathrm{Total}$ & 99.21 & 84.09 \\
\hline
\end{tabular}

\subsection{Influence of Oyster Shell (OS) Powder on BPB Plasma Treatment}

The efficacity of the incorporated OS was actually due to the acidity control of the solution by progressive dissolution of the main component of the shells, i.e.,calcium carbonate.

Weighted masses of shells were incorporated in the solution of BPB, then stirred for thirty minutes before being exposed to the plasma for $t^{*}=20 \mathrm{~min}$. The results obtained after glidarc treatments of the incorporated shells in the solution of BPB are presented in Table 3.

Table 3. Degradation rate for the plasmacatalytic treatment of BPB by Oyster shell $\left(\mathrm{t}^{*}=20 \mathrm{~min}\right)$

\begin{tabular}{|c|c|}
\hline Oyster Shell concentration (g. $\left.\mathrm{L}^{-1}\right)$ & Degradation rate (\%) \\
\hline 0 & 15.15 \\
\hline 0.1 & 07.27 \\
\hline 0.2 & 14.54 \\
\hline 0.3 & 21.21 \\
\hline 0.4 & 28.48 \\
\hline 0.5 & 27.27 \\
\hline 0.6 & 23.03 \\
\hline
\end{tabular}




\subsection{Post-Discharge Phenomena for $\mathrm{TiO}_{2}$ or OS Powder Containing Dye Solution}

The solutions of BPB containing either titanium oxide or OS powder were first exposed to the discharge (for $t^{*}=20 \mathrm{~min}$ ) and then kept for an incubation time $t_{\mathrm{PD}}$, out of the discharge in the dark and at ambient temperature. Post-discharge kinetic evolution of the Bromophenol Blue solutions in the presence of incorporated $\mathrm{TiO}_{2}\left(1-2\right.$ and 3 g. $\left.\mathrm{L}^{-1}\right)$ or $\mathrm{OS}$ $\left(0.4 \mathrm{~g} . \mathrm{L}^{-1}\right)$ was followed by absorbance measurements at the $438 \mathrm{~nm}$ peak. A decrease in the absorbance with the post-discharge time $\left(t_{\mathrm{PD}}\right)$ was observed as shown Fig. 10.

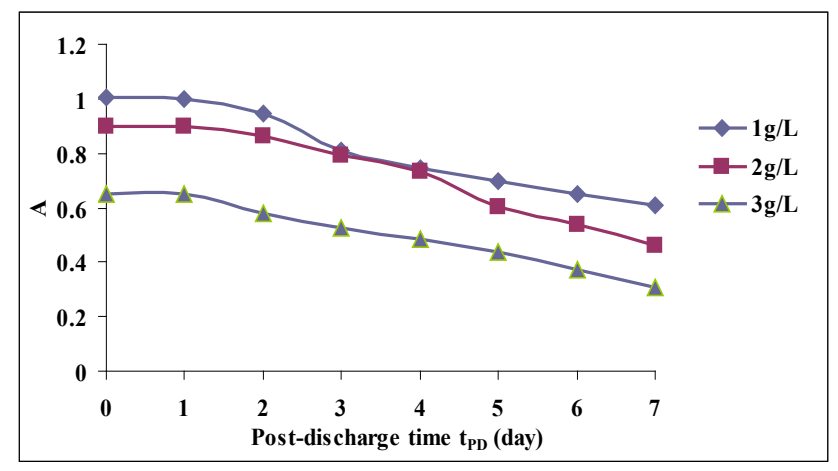

Figure 10. Evolution of the absorbance against post- discharge time $t_{\mathrm{PD}}$ (day), $\mathrm{TiO}_{2}$ catalyst, $\mathrm{m}=1,2,3$ g. $\mathrm{L}^{-1}$

The abatement values obtained in post-discharge conditions of plasma treated solutions coupled with $\mathrm{TiO}_{2}$ are gathered in Table 4. After 7 days of post discharge, the dye abatement of solutions with incorporated $3 \mathrm{~g} \cdot \mathrm{L}^{-1}$ of $\mathrm{TiO}_{2}$ and exposed to the discharge for $20 \mathrm{~min}$ reaches $82.05 \%$.This value is higher compared to the values obtained for solutions treated with 1 and 2 g. $\mathrm{L}^{-1}$ of titanium oxide. It should be noted that the observed phenomenon of post-discharge is more pronounced for a mass of 2 g.L. ${ }^{-1}$ of $\mathrm{TiO}_{2}$.

Table 4. Variation of Degradation rate (\%) with Post-discharge time $t_{P D}$ (day) and Mass $\mathrm{m}\left(\mathrm{g} . \mathrm{L}^{-1}\right)$ of $\mathrm{TiO}_{2}$

\begin{tabular}{|c|c|c|c|}
\hline \multirow{2}{*}{$t_{\mathrm{PD}}($ day $)$} & \multicolumn{3}{|c|}{${\mathrm{Mass} \mathrm{TiO}_{2}\left(\mathrm{~g} . \mathrm{L}^{-1}\right)}$} \\
\cline { 2 - 4 } & 1 & 2 & 3 \\
\hline 0 & 39.81 & 46.18 & 61.21 \\
\hline 1 & 39.96 & 46.23 & 61.31 \\
\hline 2 & 43.32 & 48.31 & 65.32 \\
\hline 3 & 51.38 & 52.46 & 68.74 \\
\hline 4 & 55.32 & 56.06 & 71.32 \\
\hline 5 & 58.30 & 64.02 & 74.08 \\
\hline 6 & 61.22 & 68.03 & 78.12 \\
\hline 7 & 63.56 & 72.63 & 82.05 \\
\hline
\end{tabular}

The OS powder $\left(0.4\right.$ g.L $\left.\mathrm{L}^{-1}\right)$ incorporated to the solution and exposed to the discharge for $20 \mathrm{~min}$, then abandoned in post-discharge conditions for the same period of one week confirmed the occurrence of temporal post-discharge reaction (TPDR); the abatement increased by $42 \%$ from $28.8 \%$ to $70.9 \%$ without any external input energy. Table 5 reports the relevant abatements with a daily post-discharge time.

\subsection{Kinetics of Post-Discharge Reactions}

The plots relevant to incorporated titania do not obviously verify a standard kinetic model except for $t_{\mathrm{PD}}$ times longer than 1 day. In these conditions, the logarithm transforms $\mathrm{LnA}=\mathrm{f}\left(\mathrm{t}_{\mathrm{PD}}\right)$ are reasonably linear (Fig.11) and the kinetic constants (resp: $0.08-0.11$ and 0.12 day $^{-1}$ for $1-2$ and 3 g. $\mathrm{L}^{-1}$ incorporated $\mathrm{TiO}_{2}$ ) increase with the concentration in photo-catalyst.

Table 5. Variation of Degradation rate (\%) with Post-discharge time $t_{\mathrm{PD}}$ (day) and Mass of Natural Oyster Shell $\left(\mathrm{m}=0.4 \mathrm{~g} . \mathrm{L}^{-1}\right)$

\begin{tabular}{|c|c|}
\hline$t_{\mathrm{PD}}($ day $)$ & Degradation rate $(\%)$ \\
\hline 0 & 28.48 \\
\hline 1 & 44.30 \\
\hline 2 & 51.21 \\
\hline 3 & 54.67 \\
\hline 4 & 59.81 \\
\hline 5 & 65.21 \\
\hline 6 & 69.15 \\
\hline 7 & 70.90 \\
\hline
\end{tabular}

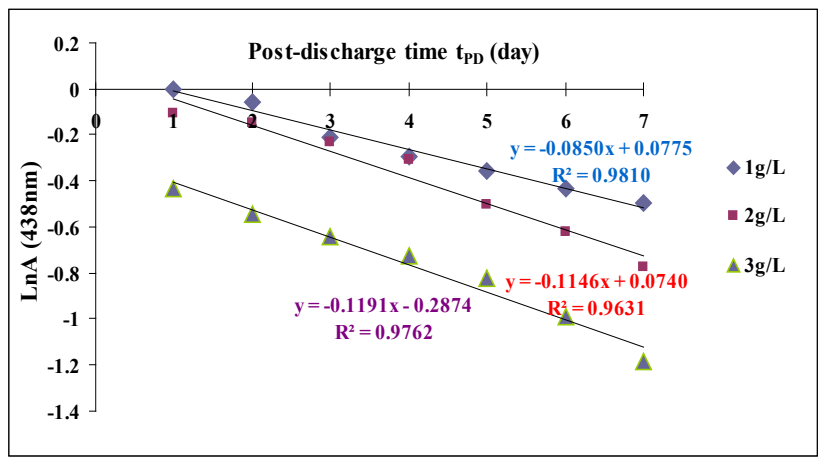

Figure 11. Evolution of logarithm of absorbance against post- discharge time t $t_{P D}$ (day), with $\mathrm{TiO}_{2}$ catalyst)

Such a result could be expected because the higher is the mass of incorporated titania, the more numerous the population of $\bullet \mathrm{OH}$ photocatalytically formed for low catalyst concentrations.

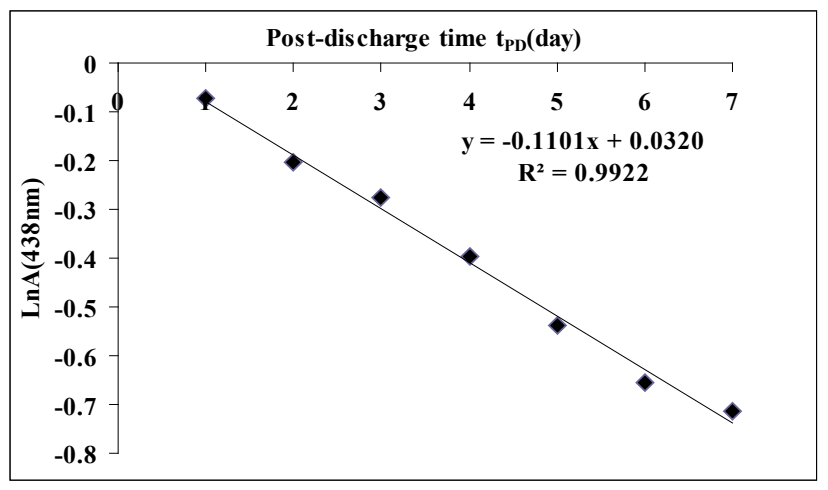

Figure 12. Evolution of logarithm of absorbance against post- discharge time $t_{P D}$ (day), with Oyster shell catalyst $\left(\mathrm{m}=0.4 \mathrm{~g} \cdot \mathrm{L}^{-1}\right)$ 
The evolution with $\mathrm{t}_{\mathrm{PD}}$ of the $438 \mathrm{~nm}$ absorbance peak $\left(\mathrm{A}_{438}\right)$ of the plasma treated BPB solution with OS $(\mathrm{m}=$ $0.4 \mathrm{~g} . \mathrm{L}^{-1}$ ) is more simple and $\mathrm{A}_{438}$ regularly decreases (Fig. 12).

The logarithm transform of $\mathrm{A}_{438}$ is linear over the 7 tested days; the resulting pseudo 1st-order law constant is then given (in day $^{-1}$ ) by the slope of the line $\mathrm{LnA}_{438}=-0.11 \mathrm{t}_{\mathrm{PD}}+$ 0.03 with $\mathrm{R}^{2}=0.992$. The kinetic constant for OS $(\mathrm{k}=0.11$ day $^{-1}$ or $0.076510^{-3} \mathrm{~min}^{-1} \approx 0.0810^{-3} \mathrm{~min}^{-1}$ ) is close to those relevant to titania but the $1^{\text {st }}$ order law is more tightly observed $\left(\mathrm{R}^{2}=0.98-0.96\right.$ and 0.98 respectively for $1-2$ and 3 g. $\mathrm{L}^{-1} \mathrm{TiO}_{2}$ incorporated).

\section{Discussion}

\subsection{Chemical Interpretation of Acid Effects and Kinetics Studies (Figure 4 and 5)}

The acid effects of a plasma treatment were already evidenced and quantified several decades ago [29,30] on exposing aqueous solutions or indicators trapped in a gel to the neutral species of a corona discharge in ambient air. We studied here the same effects by exposing the aqueous solution of BPB to the gliding arc discharge in humid air. The species present in the plasma and considered to be responsible for the acid effect are the nitrogen oxides, among which the most important is $\bullet \mathrm{NO}$, which was incidentally identified and quantified from emission spectroscopy analysis [24]. The overall reaction involves air nitrogen and oxygen as the starting species and occurs in the arc. The overall reactions are as follows:

$$
\begin{aligned}
& \mathrm{N}_{2}+\mathrm{O}_{2} \rightarrow 2^{\bullet} \mathrm{NO} \\
& \bullet \mathrm{NO}+1 / 2 \mathrm{O}_{2} \rightarrow \mathrm{NO}_{2} \\
& \mathrm{NO}_{2}+\mathrm{HO}^{\bullet} \rightarrow \mathrm{H}^{+}+\mathrm{NO}_{3}^{-}
\end{aligned}
$$

The disappearance of the basic form of the dye (Fig. 6) obeys an overall $1^{\text {st }}$ order kinetic law, as it was expected [31] for dilute solutions. The relevant constant, $\mathrm{k}_{1}=0.216 \mathrm{~min}^{-1}$ $\left(\mathrm{k}_{1}=0.004 \mathrm{~s}^{-1}, \mathrm{R}^{2}=0.99\right)$, was given by the slope of the linear plot of $\operatorname{Ln}\left(A-A_{i n f}\right)=f\left(t^{*}\right)$ with $A_{i n f}=0.230$ (Fig. 13).

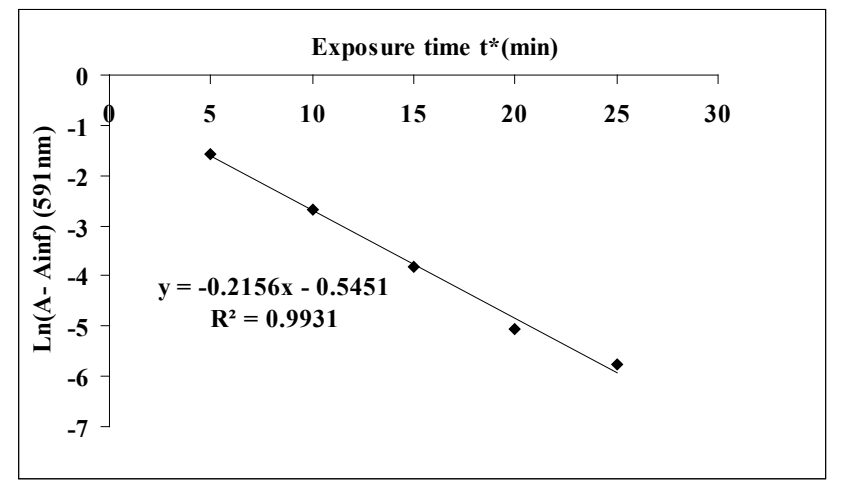

Figure 13. Kinetics of basic BPB solutions exposed to the discharge for t*min. The absorbance spectra are given in Fig. 4.
The same order $\left(1^{\mathrm{st}}\right)$ of kinetic model is obtained for the appeareance of acid form (Fig. 14), with the value of kinetic constant $\mathrm{k}_{2}=0.093 \mathrm{~min}^{-1}\left(\mathrm{k}_{2}=0.002 \mathrm{~s}^{-1}, \mathrm{R}^{2}=0.97\right)$. It is admitted in solution chemistry that the proton exchange reactions are among the most rapid ones. We can thus assume that the $\mathrm{pH}$ lowering occurs before any attack of the plasma active species at the target molecule, although the formation of transient nitrous and peroxynitrous acids and ultimately that of nitric acid requires a complicated scheme. We are now investigating with the degradation of BPB in acidic medium and the checking whether the degradation process takes place or not.

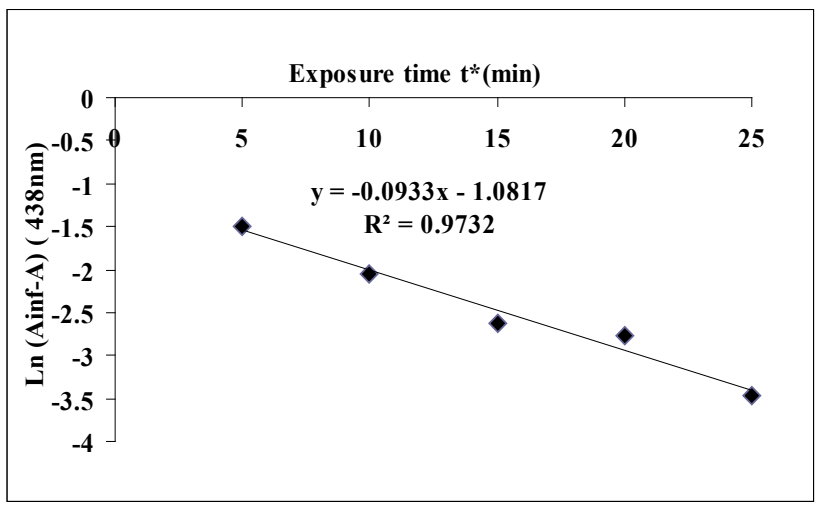

Figure 14. Kinetics of BPB solution obtain for the appeareance of acid form.

\subsection{Immediately Observation and Spectroscopic Analysis for $\mathrm{TiO}_{2}$ Used (Figure 9 and Table 1)}

The composition of discharges in humid air was investigated several years ago by emission spectrometry [24] and showed the presence of $\bullet \mathrm{OH}$ and $\bullet \mathrm{NO}$ radicals which were also quantified. The light emitted by the gliding discharge is rich in UV radiations and the occurrence of photo-sensitive catalyst such as $\mathrm{TiO}_{2}$ (anatase) might also improve the formation of active $\cdot \mathrm{OH}$ due to the ability of titania to dissociate adsorbed water molecules [32], according to "(23)" and "(24)":

$$
\begin{array}{r}
\mathrm{TiO}_{2}+\mathrm{h} v \rightarrow \mathrm{e}^{-}+\mathrm{h}^{+} \\
\mathrm{H}_{2} \mathrm{O}+\mathrm{h}^{+} \rightarrow \mathrm{HO} \bullet+\mathrm{H}^{+}
\end{array}
$$

where $\mathrm{h}^{+}$refers to a positive hole. Hence the degradation of the dye is expected to be improved by the coupling the methods. Photocatalytic treatments involve the incorporation of the solid photo-catalyst in the aqueous solution and the exposure of the resulting suspension to the UV plasma radiations for time $t^{*}$.

The adsorption of the dye on the surface of the photocatalyst was first investigated by stirring the aqueous BPB solution in the dark for $30 \mathrm{~min}$ in a flask containing various masses of the photocatalyst (0- 0.5- 1- 1.5-2- 2.5 and $\left.3 \mathrm{~g} \cdot \mathrm{L}^{-1}\right)$. Analysis of the centrifuged samples indicates no observable loss of the dye, confirming that the photo-catalytic action concerns the water molecules and not the dye. 
Spectroscopic analysis of the relevant spectra (Fig. 9) requires some comments. Firstly, a slight decrease in the absorbance peaks of the initial untreated solution is observed for the same solution exposed for 20 min without $\mathrm{TiO}_{2}$ $\left(0 \mathrm{~g} . \mathrm{L}^{-1}\right)$ : this feature confirms the occurrence of the plasma treatment. Secondly, a shoulder around $400-410 \mathrm{~nm}$ which is related to a shift of the peak wavelength suggests the formation of the $\mathrm{H}_{2} \mathrm{O}_{2}-\mathrm{TiO}_{2}$ complex in limited concentration, which agrees with the occurrence of plasma generated $\bullet \mathrm{OH}$ and its matching dimer. For higher quantities of incorporated titania, the absorbance peak decreases illustrating the influence of the photo-catalyst. No new absorption band is observed in the explored wavelengths range. These results show that titanium oxide could be the appropriate catalyst to be used for the degradation of BPB despite the increased running cost of the process.

\subsection{Potential Oxidation and Buffer Character of OS (Table 3)}

The coupled treatment of non-thermal plasma of gliding arc type with Oyster shell (OS) powder in aqueous solution for depollution purposes was studied for the first time for the pollution abatement of surface waters samples in brooks passing through large Cameroonian cities and collecting industrial and domestic wastes [17]. Our results (Table 3) show that for any concentration higher than $0.4 \mathrm{~g} . \mathrm{L}^{-1}$, other factors could affect degradation. The solution acidity accounted by $\mathrm{pH}$, is probably the determining factor in case that oxidation processes are involved. Assuming that the concerned oxidizers are $\mathrm{H}_{2} \mathrm{O}_{2}\left[\mathrm{E}^{\circ}\left(\mathrm{H}_{2} \mathrm{O}_{2} / \mathrm{H}_{2} \mathrm{O}\right)=1.76 \mathrm{~V} / \mathrm{SHE}\right]$ or to a lesser extent the monomer $\bullet \mathrm{OH}$, due to its short lifetime, and $\mathrm{ONOOH}\left[\mathrm{E}^{\circ}\left(\mathrm{ONOOH} / \mathrm{NO}_{2}\right)=2.04 \mathrm{~V} / \mathrm{SHE}\right]$ which splits in $\bullet \mathrm{OH}$ an $\bullet \mathrm{ONO}$, and a Phenol $\Phi O H$ as the organic waste whose acidity constant is that of BPB, i.e., 4.06. For $\mathrm{pH}<4.06$, the formal potential for phenol is $\mathrm{E}^{\prime \circ} \approx$ $0.1-(2.3 \mathrm{RT} / \mathrm{F}) \mathrm{pH}$ and linearly decreases with $\mathrm{pH}$, as does $\mathrm{E}^{\prime \circ}\left(\mathrm{H}_{2} \mathrm{O}_{2} / \mathrm{H}_{2} \mathrm{O}\right)$ with the same slope in the same acidity range. The reaction rate which is associated with $\mathrm{E}^{\prime \circ}\left(\mathrm{H}_{2} \mathrm{O}_{2} / \mathrm{H}_{2} \mathrm{O}\right)-\mathrm{E}^{\circ}\left(\Phi \mathrm{O} \bullet^{-} / \Phi O H\right)$ is thus constant over the considered $\mathrm{pH}$ range. For $\mathrm{pH}>4.06$, the organic reducer is the basic form $\Phi \mathrm{O}^{-}$of Phenol and the formal potential becomes $\mathrm{pH}$ independent. The difference $-\Delta \mathrm{G}^{\prime \circ} \approx$ $\mathrm{E}^{\prime \circ}\left(\mathrm{H}_{2} \mathrm{O}_{2} / \mathrm{H}_{2} \mathrm{O}\right)-\mathrm{E}^{\circ}\left(\Phi \mathrm{O}^{\circ} / \Phi \mathrm{O}^{-}\right)$decreases with increasing $\mathrm{pH}$ but never becomes nil for $\mathrm{pH}<14$. This rapid study shows that the oxidizing degradation of phenol/Phenate by $\mathrm{H}_{2} \mathrm{O}_{2}$ occurs within the whole $\mathrm{pH}$ range but the kinetic rate becomes $\mathrm{pH}$-dependent and decreases in basic media.

We chose acidic media for our working conditions, so that $\mathrm{pH}$ remains smaller than 4 and thus the kinetics are not affected by acidity. Conversely, incorporated OS masses higher than $0.4 \mathrm{~g} . \mathrm{L}^{-1}$ might be sufficient enough to increase $\mathrm{pH}$ to much higher values than 4.06 .

\subsection{Post-Discharge and Species Concerned (Figure 10, Table 4 and Table 5)}

Temporal Post-Discharge phenomena refer to the self-evolution of plasma treated solutions after switching off the discharge. Temporal Post-Discharge Reactions (TPDR) are developed in the isolated target solution, outside the reactor and in the absence of any extra energy source added, such as light or heat $[22,33]$. Therefore the evolution of $\mathrm{NO}_{2}{ }^{-}$ to $\mathrm{NO}_{3}{ }^{-}$with post-discharge time might be considered among TPDR. Indeed, after switching off the discharge species with long life time go on reacting in solution. They induce a continuous and significant decrease in the dye concentration which could be followed every day for all along one week. The species concerned as TPDR sources are $\mathrm{H}_{2} \mathrm{O}_{2}$ and $\bullet \mathrm{NO}$ (and their derivatives), additionally to peroxonitrite (-OONO) which is probably the key reagent involved in the oxidation process. The previously reported oxidizing power of $\bullet \mathrm{OH}$ radical is a feature that concerns peroxonitrite [OONO] and peroxonitrous acid [HOONO] $\left(\mathrm{pK}_{\mathrm{a}}=6.8\right)$.

This feature confirms that post discharge reactions actually develop after the discharge is switched off and could be attributed to active plasma species passed into solution, such as $\mathrm{H}_{2} \mathrm{O}_{2}$ or $\mathrm{ONOOH}$.

\section{Conclusion}

Exposing BPB dye solutions to the gliding arc discharge in humid air evidenced the acid effect of the discharge by moving the acid/base equilibrium to the acid form. Dye degradation was readily observed; the abatement was close to $15 \%$ and was attributed to the oxidizing species formed in the discharge ${ }^{\circ} \mathrm{OH}$, the dimer $\mathrm{H}_{2} \mathrm{O}_{2}$ and peroxonitrite. Incorporating solids $\left(\mathrm{TiO}_{2}\right.$ and $\left.\mathrm{OS}\right)$ to the acid dye solutions significantly enhanced the degradation rate for $20 \mathrm{~min}$ plasma treatment up to $61 \%$ and $28.5 \%$ for $\mathrm{TiO}_{2}\left(\mathrm{~m}=3 \mathrm{~g} . \mathrm{L}^{-1}\right)$ and OS $\left(\mathrm{m}=0.4\right.$ g. $\left.\mathrm{L}^{-1}\right)$ respectively. The relevant solid quantities were optimized at $3 \mathrm{~g} \cdot \mathrm{L}^{-1}$ for the photo-catalyst $\mathrm{TiO}_{2}$ and $0.4 \mathrm{~g} . \mathrm{L}^{-1}$ for $\mathrm{OS}$ which control the $\mathrm{pH}$ of the treated solution. These experiments led us to conclude that the plasma treatment could be improved by coupling with a suitable incorporated solid and the most efficient one was $\mathrm{TiO}_{2}$.

Additionally, the degradation process was recognized as going on after the discharge was switched off. This feature confirmed the occurrence of TPDR process which was previously identified in the plasma treatments of homogeneous liquids and attributed to the water soluble species $\mathrm{H}_{2} \mathrm{O}_{2}$ and $\mathrm{ONOOH}$ formed in the discharge. The pollutant abatement obtained after 20 min exposure to the discharge with incorporated solid was then increased by $21 \%$ in the presence of $3 \mathrm{gL}^{-1} \mathrm{TiO}_{2}$ and by $42 \%$ in case of OS $\left(\mathrm{m}=0.4\right.$ g. $\left.\mathrm{L}^{-1}\right)$ in samples abandoned for 7 days in post discharge conditions.

This comparative study suggests that the photo-catalyst $\mathrm{TiO}_{2}$ is actually technically more efficient than OS to improve pollutant abatement by electric discharges, but its use notably increases the running cost of the process. Besides, the occurrence of post-discharge phenomena is confirmed 
for plasma treatments coupled with incorporated selected solids. Solid wastes, such as oyster shells, were tested at that occasion: they are cheap products, and were successfully used as a coupling with non-thermal plasma in post discharge conditions and their value was then notably enhanced. They allowed to reach pollutant abatement similar to titania at much lower cost.

\section{Acknowledgements}

The authors are grateful to the International Foundation of Science (I.F.S) for the financial of materials support given to Scholarship N ${ }^{o}$ : W/4219-1 of Nzali Serge.

\section{REFERENCES}

[1] H. Zollinger. Color chemistry-synthesis: properties and applications of organic dyes and pigments, VCH Publishers, New York, 1987.

[2] Alinsafi , F. Evenou, E.M. Abdulkarim , M.N. Pons, O. Zahraa, A. Benhammou, A. Yaacoubi, A. Nejmeddine. Treatment of textile industry wastewater by supported photocatalysis, Dyes and Pigments, 74, 439-445, 2007.

[3] M.R. Ghezzar, F. Abdelmalek, M. Belhadj, N. Benderdouche, A. Addou. Arc plasma assisted photocatalytic degradation of anthraquinonic acid green 25 in solution with $\mathrm{TiO}_{2}$, Applied Catalysis B Environmental, 72, 304-313, 2007.

[4] F. Abdelmalek, PhD dissertation, University of Mostaganem, Algeria, 2003.

[5] H. Aydin, G. Baysal, Y. Bulut. Utilization of walnut (Juglans regia) as an adsorbent for the removal of acid dyes. Desalination. Water Treatment 2, 139-147, 2009.

[6] E. Njoyim-Tamungang, $\mathrm{PhD}$ dissertation, University of Yaounde-I, Yaounde, Cameroon, 2009.

[7] Legrini, E. Oliveros, A.M. Braun, Photochemical processes for water treatment, Chemical Review, 93, 671-698, 1993.

[8] M.I. Litter. Heterogeneous photocatalysis: transition metal ions in photocatalytic systems, Applied Catalysis B Environmental, 23, 89-114, 1999.

[9] M.C. Yeber, J. Rodriguez, J. Freer, J. Baeza, H.D. Mansilla. Advanced oxidation of a pulp mill bleaching wastewater, Chemosphere, 39, 1679-1688, 1999.

[10] F. Zhang, J. Zhao, T. Shen, H. Hidaka, E. Pelizzetti, N. Serpone. $\mathrm{TiO}_{2}$-assisted photodegradation of dye pollutants II: adsorption and degradation kinetics of eosin in $\mathrm{TiO}_{2}$ dispersions under visible light irradiation, Applied Catalysis B Environmental, 15, 147-156, 1998.

[11] Y. Wang. Solar photocatalytic degradation of eight commercial dyes in $\mathrm{TiO}_{2}$ suspension, Water Research, 34, 990-994, 2000.

[12] C. Guillard, H. Lachheb, A. Houas, M. Ksibi, E. Elaloui, J.-M. Hermann. Influence of chemical structure of dyes, of $\mathrm{pH}$ and of inorganic salts on their photocatalytic degradation by $\mathrm{TiO}_{2}$. Comparison of the efficiency of power and supported $\mathrm{TiO}_{2}$. Journal Of Photochemistry and Photobiology. 158, 27-36, 2003.

[13] M. Vautier, C. Guillard, J.M. Hermann. Photocatalytic degradation of dyes in water: Case study of indigo and of indigo carmine. Journal of Catalysis, 201, 46-59, 2001.

[14] X. Liu, X. Chen, J. Li, C. Burda. Photocatalytic degradation of azo dyes by nitrogen-doped $\mathrm{TiO}_{2}$ nanocatalysts, Chemosphere, 61, 11-18, 2005.

[15] M. Karkmaz, E. Puzenat, C. Guillard, J.M. Herrmann. Photocatalytic degradation of the alimentary azo dye amaranth: Mineralization of the azogroup to nitrogen, Applied Catalysis B Environmental, 5, 183-194, 2004.

[16] W.M. Clark. Oxidation reduction potentials of organic systems - The Williams \& Wilkins Company, Baltimore, (1992).

[17] E. Njoyim, P. Ghogomu, S. Laminsi, S. Nzali, A. Doubla, J.-L. Brisset. Coupling Gliding Discharge Treatment and Catalysis by Oyster Shell Powder for Pollution Abatement of Surface Waters, Industrial Engineering of Chemical Research, 48, 9773-9780, (2009).

[18] H. Lesueur, A. Czernichowski, J. Chapelle. Dispositif de génération de plasma basse température par formation de décharges électrique glissantes, Fr. Patent 2, 639,172, 1998.

[19] Czernichowski. Gliding discharge reactor for $\mathrm{H}_{2} \mathrm{~S}$ valorization or destruction. In Non-Thermal Plasma Techniques for Pollution Control, Penetrante, B. M., Shulthesis, S. E. Eds., NATO ASI Series G, Part B; SpringerVerlag: Berlin, 1993.

[20] Czernichowski. Gliding arc. Application to engineering and environmental control, Pure Applied Chemistry, 66, 1301-1310,1994.

[21] Czernichowski, K. Wesolowska. Glidarc-assisted production of synthesis gas through partial oxidation of natural gas, Fuel, Cell Science and Engeneering Technology, 181-185, 2003.

[22] J.-L. Brisset, D. Moussa, A. Doubla, E. Hnatiuc, B. Hnatiuc, G. Kamgang Youbi, J.-M.Herry, M. Naitali, M.N. Bellon-Fontaine. Chemical Reactivity of Discharge and temporal Post-Discharge in Plasma Treatment of Aqueous Media: Examples of Gliding Discharge Treated Solutions. Industrial Engineering of Chemical Research, 47, 5761-5781, 2008.

[23] A. Doubla, L. Bouba Bello, M. Fotso, J.-L. Brisset. Plasmachemical decolourisation of Bromothymol Blue by gliding electric discharge at atmospheric pressure, Dyes and Pigments, 77, 118-124, 2008.

[24] Benstaali, P. Boubert, G. Cheron, A. Addou, J.-L. Brisset. Density and rotational temperature measurements of $\mathrm{NO}$ and $\mathrm{OH}$ radicals produced by a gliding arc in humid air and their interaction with aqueous solution, Plasma chemistry Plasma Process, 22, 553-571, 2002.

[25] M. Sahni, W. Finney, B. Locke. Quantification of hydroxyl radicals produced in aqueous phase pulsed electrical discharge reactors, Industrial Engeneering of Chemical Research, 45, 5819-5825, 2006. M. Sahni, W. Finney, B. Locke. Quantification of hydroxyl radicals produced in aqueous phase pulsed electrical discharge reactors, Industrial 
Engineering of Chemical Research, 45, 5819-5825, 2006.

[26] P. Bruggeman, T. Verreyken, M. Gonzales, J. L. Walsh, M. G. Kong, C. Leys, D.C. Schramm. Optical emission spectroscopy as a diagnostic for plasmas in liquids: opportunities and pittfalls Journal of Physical. D: Applied Physics, 43, 124005, 2010.

[27] D. Moussa, F. Abdelmalek, B. Benstaali, A. Addou, E. Hnatiuc, J.-L.Brisset. Acidity control of the gliding arc treatments of aqueous solutions: application to pollutant abatement and biodecontamination, European Physical Journal. Applied Physics, 29,189-199, 2002.

[28] J.-L. Brisset, E. Hnatiuc. Peroxynitrite a re-examination of the chemical properties of non-thermal discharges burning in air over aqueous solutions, Plasma Chemistry Plasma Process, $32,655-674,2002$.
[29] J.-L. Brisset,. A. Doubla,. J. Amouroux. Proc. ISPC-8, Tokyo, 1793-1798, 1987.

[30] J.-L. Brisset, J. Lelièvre, A. Doubla, J. Amouroux. Analusis, $18,185,1990$.

[31] D. Moussa, J.-L. Brisset. Disposal of spent tributylphosphate by gliding arc plasma. Journal of Hazardous Materials, B102, 189-200, 2003.

[32] G. Martra - Lewis acid and base sites at the surface of microcrystalline $\mathrm{TiO}_{2}$ anatase: relationships between surface morphology and chemical behaviour - Applied Catalysis A: General 200, 275-285, 2000.

[33] A. Doubla, F. Abdelmalek, K. Khelifa, A. Addou, J.-L. Brisset, Post-discharge plasma chemical oxidation of iron (II) complexes, Journal of Applied Electrochemistry, 33,73-77, 2004. 